NEWS

Japanese science faces deep cuts

The government's election promises vowed more support for science, but so far budgets look set to shrink.

Japanese researchers are in uproar about the drastic budget cuts being recommended for science projects by a new cabinet-level government advisory unit.

Since 11 November, working groups of the Government Revitalization Unit, created in September and chaired by Prime Minister Yukio Hatoyama, have been re-evaluating 220 government-funded programmes, including dozens of prominent science projects.

The drastic shake-up will hit the SPring- 8 synchrotron in Harima, a planned supercomputer that was destined to be the world's fastest, ocean drilling projects and basic grant programmes, to name but a few.

The recommendations, part of an effort to trim $¥ 3$ trillion (US $\$ 33.7$ billion) off next year’s budget, are the most concrete indication so far that Japan's new government intends to make comprehensive, long-lasting changes to the country's research priorities.

Scientists are reacting with frustration and, in some cases, apocalyptic predictions. One prominent crystallographer, who requested anonymity, told Nature: "If this goes on, Japanese scientists, including young scientists, will flow overseas, and Japanese science will die."

Hatoyama's government rode into power in August, promising to shift government expenditure from wasteful projects to initiatives that will benefit the average person, such as ending highway tolls. In August, Hatoyama told Nature that he would nonetheless increase support for science ${ }^{1}$.

But since then, his government has been slicing into budgets. In October, the science and education ministry reduced the total grants for 30 of the projects under the Funding Program for World-Leading Innovative R\&D on Science and Technology (FIRST) from $¥ 270$ billion to $¥ 100$ billion $^{2}$.

On 8 October, after chairing a meeting of the Council for Science and Technology Policy, Japan's highest science-policy body, Hatoyama noted that his cabinet is "extremely rare" because it includes several engineers, such as himself. "Because we too did research, we know that researchers and academics can get drunk on their own studies," he said, according to the economic newspaper Nihon Keizai Shimbun. "Isn't it more appropriate to promote research that matches a new social system?"
At daily hearings in Tokyo, the unit's three working groups are devoting one hour to each project under review. The sessions can be viewed live on the Internet ${ }^{3}$, and recommendations for the latest projects to be evaluated are uploaded to the website daily, with the basic message displayed in red. This is a startling amount of transparency for Japan, where budgets are usually delivered after bureaucrats strike deals in back rooms. "It's difficult to cut deals now," says Atsushi Sunami, director of science and technology policy at the National Graduate Institute for Policy Studies in Tokyo.

The 19 members of Working Group 3, which is reviewing science projects, include economists, a financial strategist, local government officials and other representatives of the public, along with a few scientists. It is usually ministry officials, not scientists, who have had to defend the projects under review.

The working group has already recommended that the $¥ 10.8$ billion annual budget of SPring-8, the merits of which "were not adequately explained", be cut by one-third to onehalf and be supplemented by charging users.

"The cuts to SPring- 8 are devastating," says

\title{
Plant genetics database at risk as funds run dry
}

The world's most valued plant database faces extinction because its funding is being phased out by the US National Science Foundation (NSF), and no alternative source is on the horizon.

"This is the wrong way to go," says genomics researcher Ernest Retzel of the National Center for Genome Resources in Santa Fe, New Mexico. "I believe it will set the field back."

The NSF says that it does not have a policy to support long-term, established research-infrastructure projects such as the Arabidopsis Information Resource (TAIR), which maintains a free, openaccess database of genetic and molecular-biology data for

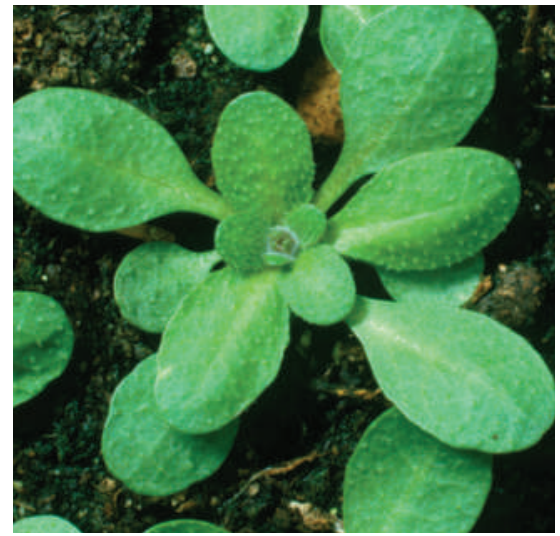

The popular model plant Arabidopsis thaliana.

Arabidopsis thaliana, or thale cress, the widely used model plant. "We didn't approach this decision in isolation, we considered our whole portfolio," says Peter Arzberger, director of the Division of Biological
Infrastructure at the NSF. "We rely on peer review in setting our priorities." The NSF has suggested that TAIR develop its own self-supporting funding model, based on user subscriptions and other sources of income.

But TAIR director Eva Huala told an international meeting on database and bioresource sustainability, held in Rome on 11-12 November, that introducing a subscription system would destroy, not save, TAIR.

Huala, a member of the Department of Plant Biology at the Carnegie Institution for Science in Stanford, California, presented preliminary results of a survey among TAIR users, which revealed that many would be reluctant to submit data to TAIR if these were not freely shared.

Established ten years ago, TAIR integrates data submitted by the community with data extracted from the literature, and it has evolved into the plant community's foremost authority on matters relating to plant genomics, regulating nomenclature and developing curation standards. It is much more widely used than other plant databases because of its all-inclusive nature and the quality of its curation.

TAIR also feeds information into other specialist databases, such as those of the National Center for Biotechnology Information in Bethesda, Maryland, and the international protein database UniProt. In addition, it links to the Arabidopsis Biological Resource 


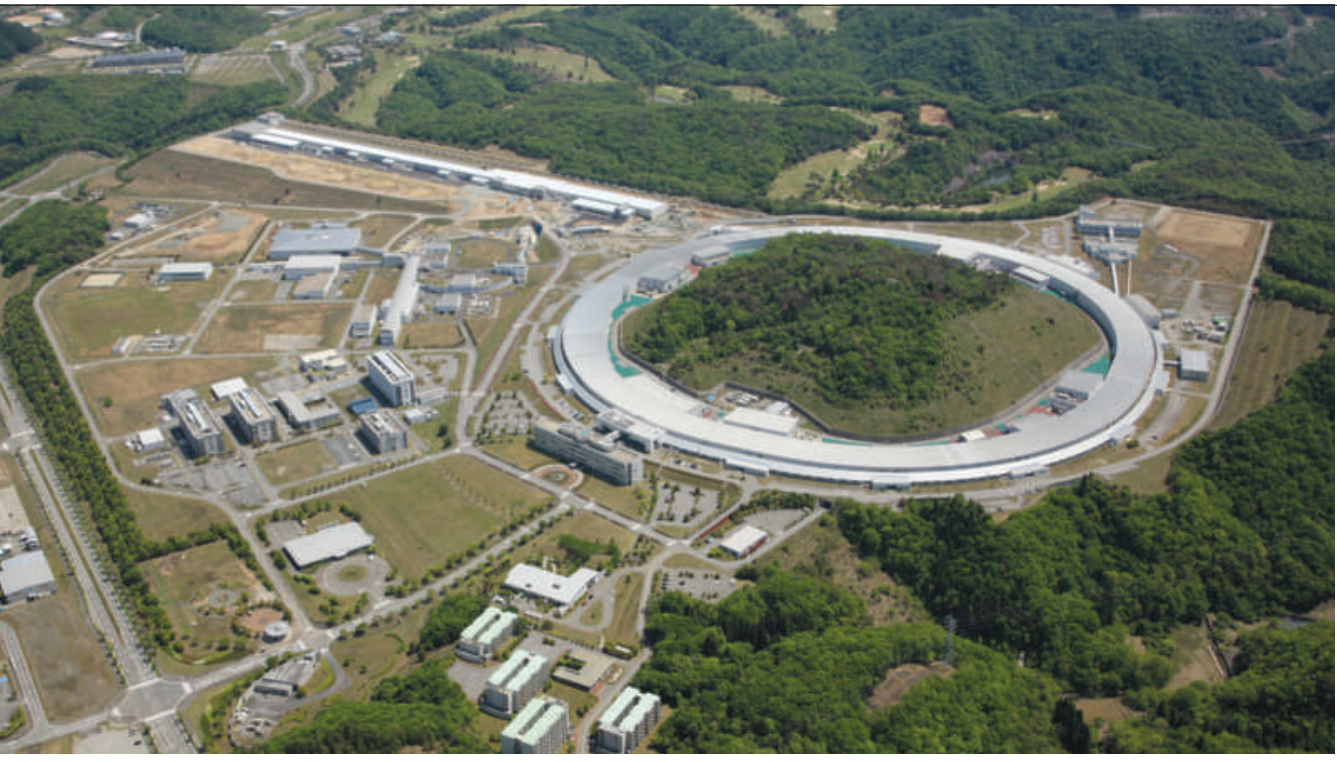

The SPring-8 synchrotron facility faces proposed cuts of one-third to one-half of its budget.

structural biologist Soichi Wakatsuki, director of the KEK Photon Factory in Tsukuba and a collaborator with SPring-8. "There's no other synchrotron in the world that is supposed to earn so much of its own income." He laments the review process as "one-sided", adding that researchers are given "no real chance" to defend their projects. Tomitake Tsukihara, a crystallographer at the University of Hyogo, adds that protein crystallography and other basic science done at SPring- 8 will suffer, and is organizing a protest in response to the recommendation.

A supercomputer planned by RIKEN, Japan's network of research labs, had already been thrown into confusion by the sudden departure of electronics giants NEC and Hitachi from the project earlier this year ${ }^{4}$. The project should now be "virtually eliminated", says the working group, which saw no need for Japan to host the world's fastest supercomputer.

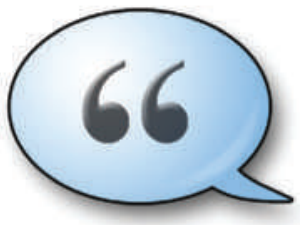

HAVE YOUR SAY

Comment on any of our News stories, online.

www.nature.com/news

Other recommendations made by the group include slashing the funding for RIKEN's BioResource Center and its Plant Science Center, with budget cuts of one-third proposed for each; cutting Japan's deep-sea-drilling programme by $10-20 \%$; and at least halving the budget for the Institute for Research on Earth Evolution in Yokosuka. In addition, various competitive grant programmes, including the Grants-in-Aid programme - the bread and butter of most researchers - should be "simplified and reduced". Further recommendations on a prototype Japanese-European fusion reactor, planned as part of the international ITER project to prove atomic fusion as a power source, were expected as Nature went to press.

Asked whether the proposed cuts contradict earlier pledges to increase scientific funding, or whether increases in funding to other fields will offset these proposed cuts, a representative for Hatoyama said that these issues were "under discussion".

The working groups' recommendations will be considered by the Government Revitalization Unit before being submitted to the finance ministry, which will announce its budget in late December.

David Cyranoski
1. Cyranoski, D. Nature 460, 938 (2009)
2. Cyranoski, D. Nature 461, 854-855 (2009).
3. http://www.cao.go.jp/sasshin/
4. Cyranoski, D. Nature doi:10.1038/news.2009.495 (2009).

Center in Columbus, Ohio, which provides seed and DNA resources to researchers.

TAIR has been supported by two consecutive five-year NSF grants, the second of which came to an end on 31 August. The NSF is planning to maintain the current budget of $\$ 1.6$ million for 2010 , and then to phase out funding over the following three years (see graph).

\section{PHASED-OUT FUNDING}

National Science Foundation funding for the Arabidopsis Information Resource is being phased out.

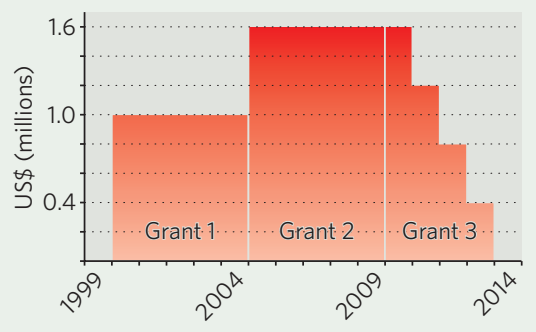

Huala's survey, sent on 4 November to more than 900 TAIR users, asked respondents which of TAIR's features are most important and which could feasibly be sacrificed in the hunt for alternative funding mechanisms. The majority of the $\mathbf{2 5 0}$ or so responses she has received so far say that there should be no log-in requirement, that everyone should have equal, free access to the data, and that data should continue to flow freely into other databases.

Around two-thirds said they would be less likely to submit data to TAIR if these were not then freely shared with all researchers.

Respondents said that they would accept a situation in which publicly funded institutions and individuals had free access, but companies were required to buy subscriptions. They also said that they would be happy for advertising to appear on the website to raise revenue. But Huala says that neither measure would raise enough money to sustain the database.

"As soon as we introduce any form of subscription, we would not be able to export information to other free, open-access databases as we do now," she says. "The whole system would break down."

If TAIR were lost, another free database would inevitably spring up to take its place, thereby fragmenting the community, she adds. "The self-supporting models proposed by the NSF are more like a track to extinction."

Huala has put out feelers to other potential funding sources in the United States, and also to other countries, because only around a quarter of TAIR users are US-based.
"But these are all long shots," she admits. "I am not optimistic."

Along with the Multinational Arabidopsis Steering Committee, which represents Arabidopsis researchers, the NSF is planning workshops for $\mathbf{2 0 1 0}$ to gather input from members of the Arabidopsis community on their database and informatics needs.

The plight of TAIR is the most recent and most drastic example of funding crises now facing many databases and bioresources, says Paul Schofield, a molecular geneticist at the University of Cambridge, UK, who coordinated the Rome meeting. "There is a disparity between what science needs and available funding instruments for infrastructure," he says. "National research agencies need to get together to design new strategies."

Alison Abbott

See Editorial, page 252. 